Article

\title{
Conversion of South African Coal Fly Ash into High-Purity ZSM-5 Zeolite without Additional Source of Silica or Alumina and Its Application as a Methanol-to-Olefins Catalyst
}

\author{
Roland N. M. Missengue ${ }^{1, *, \dagger}{ }^{,}$Pit Losch ${ }^{2}$, Nicholas M. Musyoka ${ }^{3}$, Benoit Louis ${ }^{2}$, Patrick Pale ${ }^{2}$ \\ and Leslie F. Petrik ${ }^{1}$ \\ 1 Department of Chemistry, University of the Western Cape, 7535 Cape Town, South Africa; lpetrik@uwc.ac.za \\ 2 Institute of Chemistry, UMR 7177, University of Strasbourg, CNRS, 67000 Strasbourg, France; \\ pit.losch@gmail.com (P.L.); blouis@unistra.fr (B.L.); ppale@unistra.fr (P.P.) \\ 3 Council for Scientific and Industrial Research, 0001 Pretoria, South Africa; nmusyoka@csir.co.za \\ * Correspondence: rmissengue@gmail.com; Tel.: +27-(0)72-293-3475 \\ + Current address: Department of Research and Development, AgriProtein Technologies, 7750 Cape Town, \\ South Africa.
}

Received: 19 October 2017; Accepted: 14 November 2017; Published: 21 March 2018

\begin{abstract}
Characteristics of ZSM-5 synthesized from $\mathrm{H}_{2} \mathrm{SO}_{4}$-treated coal fly ash and fused coal fly ash extracts are compared in this study. In the synthesis process, fused coal fly ash extract (without an additional silica source) was used in the synthesis of ZSM-5. The effect of the structure-directing agent (tetrapropylammonium bromide, 1,6-hexanediamine or 1-propylamine) on the properties and methanol-to-olefins (MTO) effectiveness of the fly ash-based ZSM-5 was also investigated. A pure ZSM-5 synthesized from the fused coal fly ash extract led to a methanol conversion higher than $90 \%$ after $5 \mathrm{~h}$ on stream. The template 1,6-hexanediamine led to the synthesis of the most stable fly ash-based catalyst keeping a $44 \%$ methanol conversion after $24 \mathrm{~h}$ on stream.
\end{abstract}

Keywords: coal fly ash; coal fly ash extract; oxalic acid treatment; structure-directing agent; ZSM-5 and methanol-to-olefins

\section{Introduction}

The fly ash has been used as a starting material for the synthesis of zeolites because of its high content of amorphous aluminosilicate glass [1]. Several routes to prepare various zeolite types have been suggested based on the pre-treatment of the fly ash, alkalinity of the hydrothermal solution, molarity of alkaline agents, solution/solid ratio, templating agent, time, temperature and time of incubation [2-9]. ZSM-5 is synthesized from a hydrothermal solution containing Al and Si sources, a mineralizing agent $\left(\mathrm{OH}^{-}\right.$or $\left.\mathrm{F}^{-}\right)$and an organic structure-directing agent (OSDA) [10-13], with tetrapropylammonium cation $\left(\mathrm{TPA}^{+}\right)$being the most-used OSDA $[9,14-16]$. The OSDAs that give pure ZSM-5 increase as follows: alcohols < amines < tetrapropylammonium halide. The OSDA promotes the formation of the desired building blocks in the synthesis gel and acts as a hydrophobic pore filler to prevent dissolution and recrystallization of already formed crystals [11]. Some studies have reported the synthesis of ZSM-5 zeolite without any OSDA [14]. In addition to OSDAs, other parameters that influence the crystallization as well as the morphology of ZSM-5 zeolite include Al content, template/silica ratio, water content, nature of the cations present, alkalinity, degree of polymerization of the silica and the hydrothermal synthesis conditions [17-20]. It has been reported that ZSM-5 zeolite can be synthesized from fly ash. In most cases, a source of silica needs to be added $[9,13,21,22]$, which does not promote the use of fly ash as feedstock in the synthesis of ZSM-5 at 
large scale. However, Xing and Hongyan reported the synthesis of ZSM-5 from an alkaline supernatant of a pulverized fuel ash without additional source of silicon or aluminum [23]. Moreover, the presence of other mineral phases in the final ZSM-5 product hinders its catalytic effectiveness [13].

ZSM-5 zeolite belongs to the 'big five' zeolites mainly used in catalysis and applied in several industrial processes [24]. ZSM-5 catalyst accounts for increasing the octane number of gasoline in a fluid catalytic cracking (FCC) unit and ZSM- 5 has been adopted in a large number of commercial FCC units since the initial reports in 1983 [25]. ZSM-5 has also been used to convert alcohols into hydrocarbons $[12,19,26]$. In South Africa, the methanol conversion to hydrocarbons can be exploited at an industrial scale and adds more value to coal and coal fly ash, as methanol can be synthesized from coal [27], and ZSM-5 can be produced from coal fly ash [9,13]. It was reported that the post-synthesis treatment of ZSM-5 with oxalic acid solution improved its catalytic efficiency $[13,28]$. Several studies have been conducted using fusion of fly ash with sodium hydroxide as a pre-treatment step in order to dissolve Si and Al prior to the synthesis of high-purity zeolites [3,29]. Missengue and coworkers reported that concentrated sulfuric acid (95-99\%) was used to extract aluminum from coal fly ash in order to increase the $\mathrm{Si} / \mathrm{Al}$ ratio in the fly ash solid residue that was used as feedstock for the synthesis of ZSM-5 [13].

Scientific advances made in the extraction of silica and alumina from aluminosilicate-rich raw materials [30-32] can rationalize the synthesis of zeolites from fly ash without addition of extra silica or alumina sources, since the synthesis of high-purity ZSM-5 zeolite from fly ash without the addition of a source of silica or alumina is not well developed. Hence, that is one of the objectives of this study.

\section{Results and Discussion}

The aim of the treatment of fly ash (FA) with $\mathrm{H}_{2} \mathrm{SO}_{4}$ was to remove as much aluminum as possible and moderate the use of a silica source to increase the $\mathrm{Si} / \mathrm{Al}$ as required for the synthesis of ZSM-5 zeolite $[9,13,22]$. However, Table 1 shows that the $\mathrm{Si} / \mathrm{Al}$ ratio only changed from 1.8 in FA to 2.0 in the acid-treated fly ash solid residue (AL), this was because the aluminum extraction conditions used in this study were not as severe as those used in the literature to remove a large amount of aluminum from fly ash; however, those conditions required a huge energy consumption [33,34]. Thus, in the present study, there was need to add fumed silica in order to increase the $\mathrm{Si} / \mathrm{Al}$ in the hydrothermal gel. Moreover, the use of different aluminum extraction conditions than that reported by Missengue and coworkers did not increase the $\mathrm{Si} / \mathrm{Al}$ ratio of the solid residue [13], hence there was still a need to add a source of silica; however, the substitution of tetrapropylammonium bromide (TPABr) by other structure-directing agents such as 1,6-hexanediamine (HDA) and 1-propylamine (PA) may lead to a cheaper way of synthesizing ZSM-5 from fly ash solid residue.

No solid product was formed when the silica extract before oxalic acid treatment (FFAE) and TPABr were used during the synthesis of ZSM-5 (FFAE-TPABr) even if the precursor silica extract (FFAE) had a Si / Al ratio of 10.4 (Table 1), which was within the range for the synthesis of ZSM-5 zeolite. This could be due to the high Na/Si ratio (3.0) in FFAE (Table 1), with the excess of $\mathrm{Na}$ coming from the fusion step. Indeed, Hattori and Yashina investigated the effect of $\mathrm{Na} / \mathrm{Si}$ ratio on the synthesis of ZSM-5 zeolite. They reported that below a Na/Si ratio of 0.016 , the synthesized ZSM- 5 zeolite was mixed with an amorphous phase; a pure phase of ZSM- 5 zeolite was formed when the $\mathrm{Na} / \mathrm{Si}$ ratio was between 0.016 and 0.4 and the increase in $\mathrm{Na} / \mathrm{Si}$ ratio from 0.4 was accompanied by formation of ZSM- 5 zeolite and $\alpha-\mathrm{SiO}_{2}$ [35]. Similar observations were reported by Singh and Dutta in an organic-free ZSM-5 zeolite synthesis. Moreover, they stated that the instability of the ZSM-5 zeolite was attributed to excess sodium [36]. However, in the present study, the hydrothermal gel of FFAE-TPABr had a Na/Si ratio of 4.9, which was much higher than the ratios reported by Hattori and Yashina [35]. Therefore, it can be concluded that the high sodium content in FFAE hampered the crystallization of ZSM-5 zeolite. Hence, it was important to reduce the amount of sodium as well as aluminum through the treatment of FFAE with saturated oxalic acid solution prior to the hydrothermal synthesis. It was not excluded that $\mathrm{OH}^{-}$anion used as mineralizing agent could cause thermal-stability 
problems to TPABr and hinder the synthesis of ZSM-5, as the quaternary ammonium cations can suffer Hoffman degradation in the presence of $\mathrm{OH}^{-}$at high temperature [37]. This could be the reason why Xing and Hongyan (2014) had to use $\mathrm{NH}_{4} \mathrm{~F}$ in the synthesis of ZSM-5 from an alkaline supernatant of a pulverized fuel ash without additional source of silicon or aluminum [23], as the use of fluoride anion $\left(\mathrm{F}^{-}\right)$was the breakthrough to prevent the degradation of organic structure-directing agents [10].

The percent of aluminum and sodium was reduced from $2.2 \pm 0.1 \%$ and $68.3 \pm 1.5 \%$ in FFAE to $1.9 \pm 0.1 \%$ and $12.5 \pm 0.4 \%$, respectively, after treatment with oxalic acid to produce a second silica extract called FFAE1. Oxalic acid has already been used in the post-synthesis treatment of zeolites to remove aluminum and sodium [13,38-40]. However, the use of oxalic acid in the removal of aluminum and sodium from fly ash extract, which was thereafter used as feedstock in the synthesis of ZSM-5 without the addition any silica or alumina source, has not yet been reported and this constitutes the original innovation of the current study.

Table 1. Elemental composition of materials used as MFI precursors, $n=3$.

\begin{tabular}{ccccc}
\hline Element & FA $^{(\mathbf{a})} \mathbf{( \% )}$ & AL $^{(\mathbf{b})} \mathbf{( \% )}$ & FFAE $^{(\mathbf{c})} \mathbf{( \% )}$ & FFAE1 $^{(\mathbf{d})} \mathbf{( \% )}$ \\
\hline $\mathrm{Si}$ & $54.5 \pm 0.9$ & $59.1 \pm 0.2$ & $22.6 \pm 2.5$ & $78.7 \pm 1.8$ \\
$\mathrm{Al}$ & $29.3 \pm 0.3$ & $29.2 \pm 0.1$ & $2.2 \pm 0.1$ & $1.9 \pm 0.1$ \\
$\mathrm{Na}$ & $0.0 \pm 0.0$ & $0.0 \pm 0.0$ & $68.3 \pm 1.5$ & $12.5 \pm 0.4$ \\
$\mathrm{Fe}$ & $6.9 \pm 0.1$ & $5.0 \pm 0.0$ & $0.0 \pm 0.0$ & $0.0 \pm 0.0$ \\
$\mathrm{Ca}$ & $5.7 \pm 0.2$ & $3.4 \pm 0.0$ & $6.5 \pm 0.2$ & $6.6 \pm 0.7$ \\
$\mathrm{Ti}$ & $2.0 \pm 0.1$ & $1.8 \pm 0.1$ & $0.0 \pm 0.0$ & $0.0 \pm 0.0$ \\
$\mathrm{~K}$ & $0.2 \pm 0.0$ & $1.0 \pm 0.0$ & $0.0 \pm 0.0$ & $0.0 \pm 0.0$ \\
$\mathrm{Mg}$ & $1.4 \pm 0.1$ & $0.6 \pm 0.0$ & $0.4 \pm 0.0$ & $0.3 \pm 0.0$ \\
$\mathrm{Si} / \mathrm{Al}$ & 1.8 & 2.0 & 10.4 & 41.8 \\
$\mathrm{Na} / \mathrm{Si}$ & 0.0 & 0.0 & 3.0 & 0.2 \\
\hline
\end{tabular}

(a) Fly ash, ${ }^{(b)}$ Acid-treated fly ash solid residue, ${ }^{(\mathrm{c})}$ Fly ash silica extract before oxalic acid treatment, ${ }^{(\mathrm{d})}$ Fly ash silica extract after oxalic acid treatment.

The XRD patterns (Figure 1A) show that the amorphous FFAE1 was transformed into pure H-ZSM-5 phase (H-FFAE1-TPABr, H-FFAE1-HDA and H-FFAE1-PA) as confirmed by Treacy and Higgins [41]. The use of AL as feedstock led to the formation of H-ZSM-5 mixed with unreacted quartz and mullite from the parent fly ash (H-AL-TPABr, H-AL-HDA and H-AL-PA) (Figure 1B). It can be observed that the XRD patterns of H-AL-TPABr, H-AL-HDA and H-AL-PA were similar to that of the fly ash-based ZSM-5 reported by Missengue and coworkers [13], as there was only a slight difference in the pretreatment of coal fly ash prior to the synthesis of ZSM-5. Moreover, the presence of quartz and mullite phases in the $\mathrm{H}-\mathrm{AL}-\mathrm{TPABr}, \mathrm{H}-\mathrm{AL}-\mathrm{HDA}$ and $\mathrm{H}-\mathrm{AL}-\mathrm{PA}$ affected their $\mathrm{Si} / \mathrm{Al}$ ratio that was less than 6 (Table 3) and was an indication that not all Si and Al coming from fly ash were involved in the formation of ZSM-5; therefore, the $\mathrm{Si} / \mathrm{Al}$ ratio (6) of the molar regime of the formation of ZSM-5 using AL (Table 3) could not be conclusive.

It is noteworthy that H-FFAE1-TPABr, H-FFAE1-HDA and H-FFAE1-PA were synthesized from the oxalic acid-treated coal fly ash extract (FFAE1) without an additional source of silica or alumina, which has not yet been reported in the literature. This could be achieved through treatment of the fly ash extract with a saturated oxalic acid solution prior to the hydrothermal synthesis and was inspired by the post-synthesis removal of sodium and aluminum zeolites using oxalic acid solution in order to improve their catalytic effectiveness [13,28,38,39]. The synthesis of ZSM-5 from fly ash normally requires the addition of a significant additional amount of silica to adjust the $\mathrm{Si} / \mathrm{Al}$ ratio as shown in the case of $\mathrm{H}-\mathrm{AL}-\mathrm{TPABr}, \mathrm{H}-\mathrm{AL}-\mathrm{HDA}$ and $\mathrm{H}-\mathrm{AL}-\mathrm{PA}$. Kalyankar and coworkers synthesized ZSM-5 zeolite from Indian fly ash with a $\mathrm{SiO}_{2} / \mathrm{Al}_{2} \mathrm{O}_{3}$ ratio of 3 . Silica sol was added to get a $\mathrm{SiO}_{2} / \mathrm{Al}_{2} \mathrm{O}_{3}$ ratio of 37 in the hydrothermal gel [21]. Reanvattana synthesized high-purity ZSM-5 zeolite from a mixture of fused fly ash filtrate and silica extracted from rice husk ash [22]. Chareonpanich and coworkers synthesized ZSM- 5 zeolite from Thailand fly ash with a $\mathrm{SiO}_{2} / \mathrm{Al}_{2} \mathrm{O}_{3}$ 
ratio of 1.6. Silica extracted from rice husk ash was added to adjust the $\mathrm{Si} / \mathrm{Al}$ molar ratio to 20,40 , 60, 80, 100 or 200 [9]. Missengue and coworkers synthesized ZSM-5 from South African coal fly ash after pretreatment with concentrated sulfuric acid (ratio 1:2), in a digestion vessel at $250{ }^{\circ} \mathrm{C}$ for $4 \mathrm{~h}$, and they reported that the solid material synthesized from the acid-treated solid residue was made of ZSM-5 and unreacted quartz and mullite phases from fly ash [13]. Figure 1 and Table 3 show that the size and shape of the ZSM- 5 crystals were modified based on the purity of the precursor used and the composition of the hydrothermal gel, which agreed with the variation of ZSM- 5 crystal size and shape reported in the literature $[11,17,18,42]$. It can also be observed that the use of FFAE1 led to pure H-ZSM- 5 crystals (H-FFAE1-TPABr, H-FFAE1-HDA and H-FFAE1-PA) while the H-ZSM-5 crystals of $\mathrm{H}-\mathrm{AL}-\mathrm{TPABr}, \mathrm{H}-\mathrm{AL}-\mathrm{HDA}$ and $\mathrm{H}-\mathrm{AL}-\mathrm{PA}$ were mixed with some impurities.

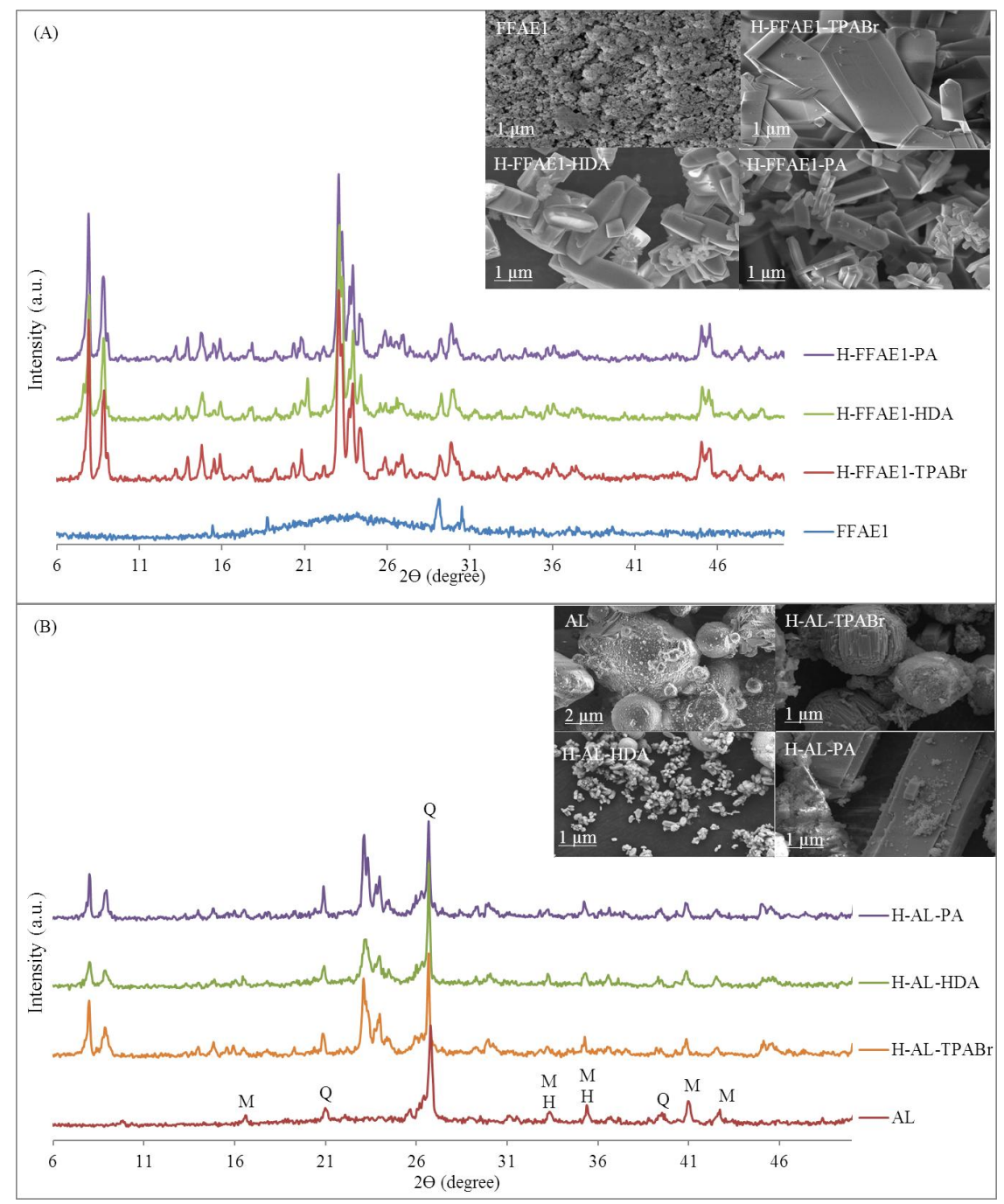

Figure 1. XRD patterns and SEM micrographs of H-ZSM-5 synthesized from FFAE1 (A) and AL (B) ( $\mathrm{M}=$ mullite, $\mathrm{Q}=$ quartz, $\mathrm{H}=$ hematite).

FTIR spectra (Figure 2A) show that the FFAE1 bands were characteristic of the amorphous silica [43]. The appearance of the double five-ring lattice vibration at $553 \mathrm{~cm}^{-1}$ [16] in H-FFAE1-TPABr, H-FFAE1-HDA and H-FFAE1-PA spectra is further confirmation of the transformation of the amorphous FFAE1 into ZSM-5. Moreover, the bands at 946 and $1060 \mathrm{~cm}^{-1}$ in the FFAE1 spectrum characterize the degree of condensation of $\mathrm{SiO}^{-}$species and correspond to the monomeric or dimeric $\mathrm{SiO}^{-}$species and rings formed by condensation of $\mathrm{SiO}^{-}$species, while the band that appears at $1123 \mathrm{~cm}^{-1}$ in H-FFAE1-TPABr, H-FFAE1-HDA and H-FFAE1-PA spectra correspond to the polymers 
of $\mathrm{SiO}^{-}$species [44]. The disappearance the monomeric or dimeric $\mathrm{SiO}^{-}$species and appearance of polymerized $\mathrm{SiO}^{-}$species in H-FFAE1-TPABr, H-FFAE1-HDA and H-FFAE1-PA is another indication of the zeolitization of FFAE1. Furthermore, the degree of crystallinity of H-FFAE1-TPABr, H-FFAE1-HDA and H-FFAE1-PA was estimated via their optical density ratio, determined using the $\mathrm{Si}-\mathrm{O}-\mathrm{Si}$ bend and double ring vibration bands at 445 and $553 \mathrm{~cm}^{-1}$, respectively $[11,45]$. The optical density ratios of H-FFAE1-TPABr, H-FFAE1-HDA and H-FFAE1-PA were 0.96, 0.89 and 0.94 respectively, which led to the conclusion that the degree of crystallinity decreased as follows: H-FFAE1-TPABr > H-FFAE1-PA > H-FFAE1-HDA. These values were close to that of a pure ZSM-5 (0.8), reported in the literature [16]. The trend in crystallinity of H-FFAE1-TPABr, H-FFAE1-HDA and H-FFAE1-PA remains similar to their XRD patterns that show pure ZSM-5 phases (Figure 1A). However, van der Gaag and coworkers investigated the effect of several templates (1,6-hexanediol, 1,6-hexanediamine, 1-propanol, 1-propanamine, pentaerythritol and tetrapropylammonium bromide) on the synthesis of ZSM-5 using pure chemicals and reported that only 1,6-hexanediamine and tetrapropylammonium bromide led to high crystallinity [46]. Figure 2B shows several bands in AL spectrum, which can result from the deconvolution of the original FA bands [47]. H-AL-TPABr, H-AL-HDA and H-AL-PA have similar bands to H-FFAE1-TPABr, H-FFAE1-HDA and H-FFAE1-PA. However, the optical density ratio of $\mathrm{H}-\mathrm{AL}-\mathrm{TPABr}, \mathrm{H}-\mathrm{AL}-\mathrm{HDA}$ and $\mathrm{H}-\mathrm{AL}-\mathrm{PA}$ may not be conclusive in determining their degree of crystallinity as the $\mathrm{Al}-\mathrm{O}$ stretch $\left(\mathrm{AlO}_{6}\right)$ vibrational band of the starting material $(\mathrm{AL})$ and double five-ring lattice vibration of the final products $(\mathrm{H}-\mathrm{AL}-\mathrm{TPABr}, \mathrm{H}-\mathrm{AL}-\mathrm{HDA}$ and H-AL-PA) may overlap between $546 \mathrm{~cm}^{-1}$ and $579 \mathrm{~cm}^{-1}$, and as the XRD patterns of H-AL-TPABr, H-AL-HDA and H-AL-PA still had an unreacted mullite phase from the AL precursor (Figure 1B).

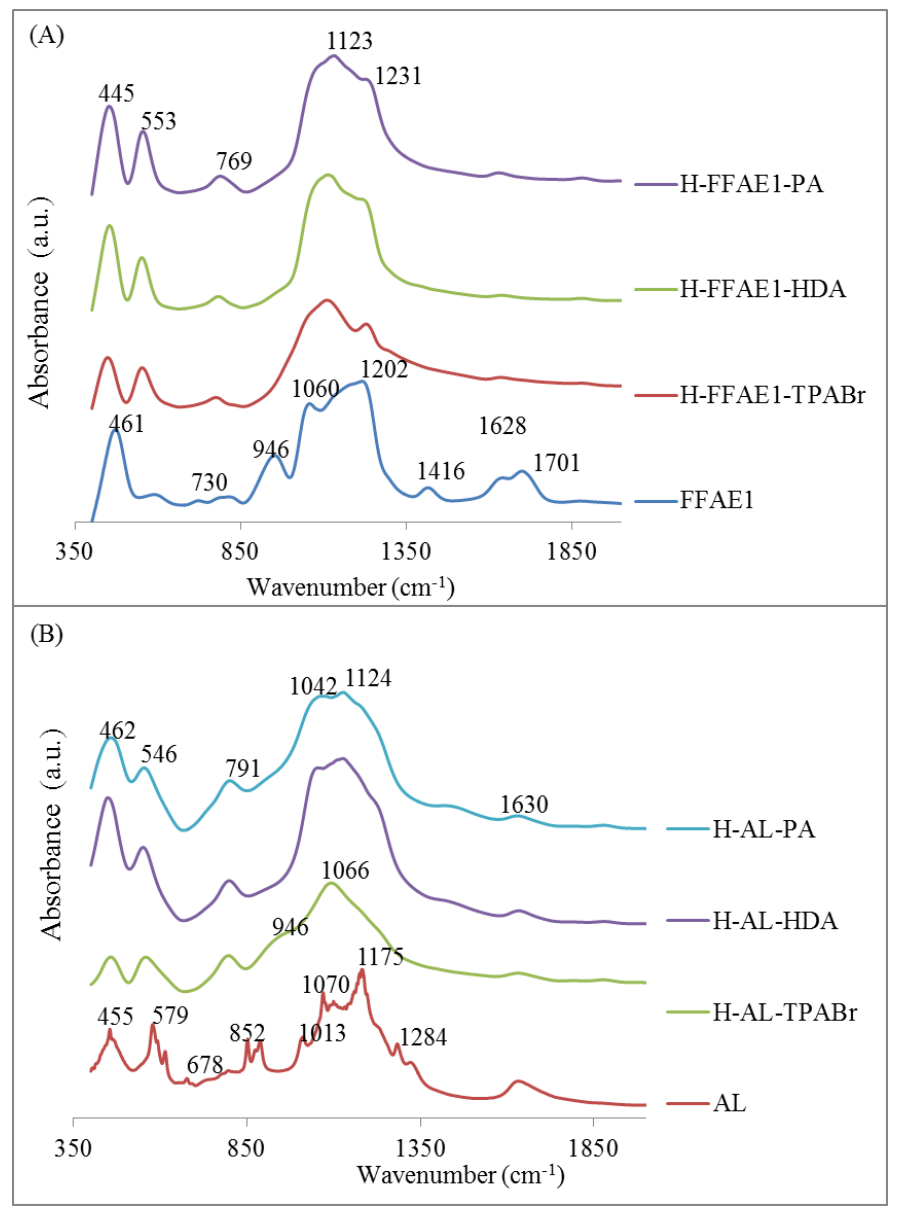

Figure 2. FTIR spectra of ZSM-5 synthesized from FFAE1 (A) and AL (B). 
In aluminum nuclear magnetic resonance $\left({ }^{27} \mathrm{Al}-\mathrm{NMR}\right)$ spectra (Figure 3$)$, the signal that corresponds to the extra framework-coordinated aluminum in FFAE1 and AL spectra (at about $0 \mathrm{ppm}$ ) is converted into a signal that corresponds to the framework-coordinated aluminum in H-AL-TPABr, H-AL-HDA, H-AL-PA, H-FFAE1-TPABr, H-FFAE1-HDA and H-FFAE1-PA (at about 55 ppm), as confirmed by Triantafyllidis and coworkers [48], and Sazama and coworkers [40]. The broad signal located at 0 ppm in FFAE1 may be due to the distortions of the octahedral symmetry of the $\mathrm{AlO}_{6}$ units as it was stated by Byrappa and Yoshimura [49] and Sazama and coworkers [40].

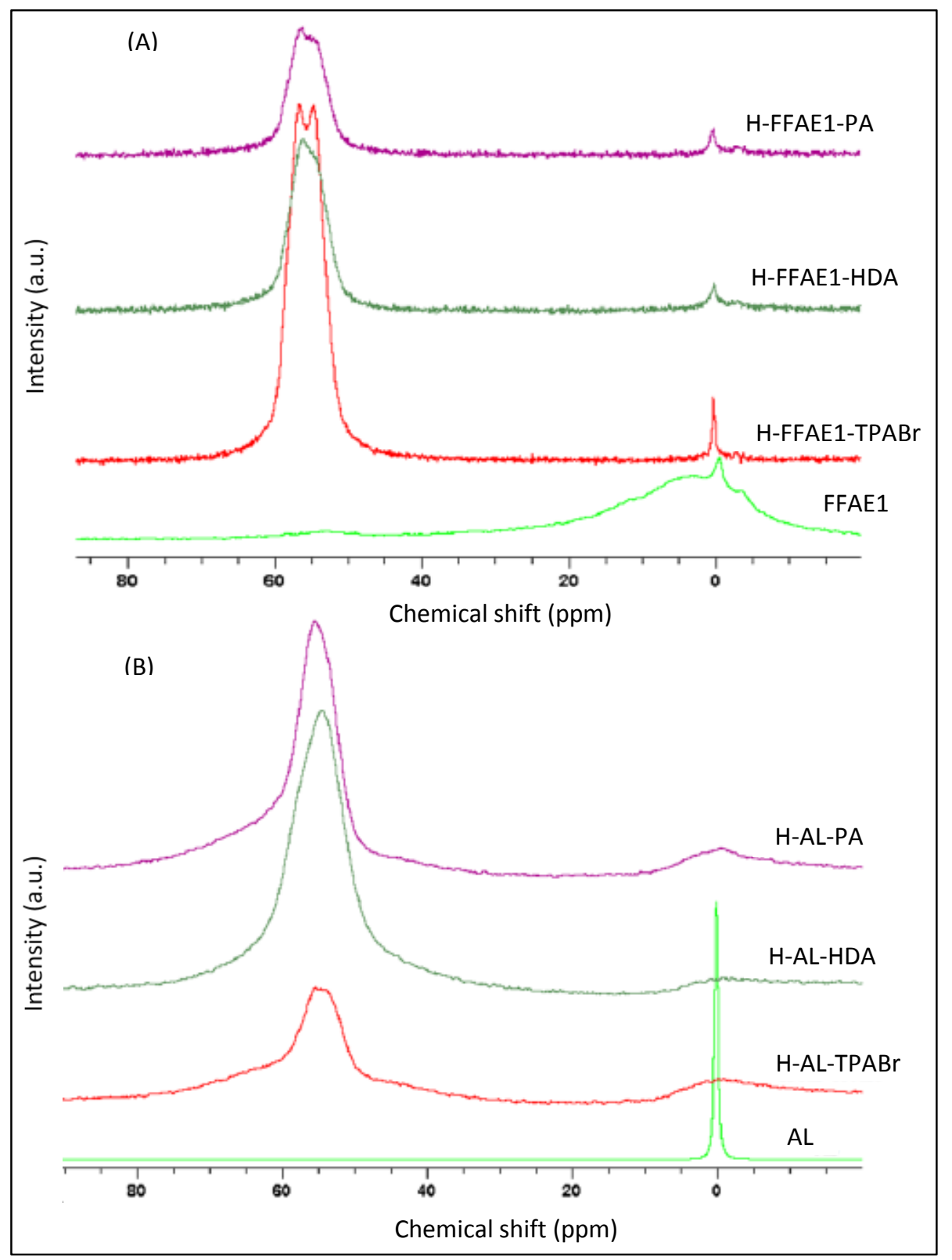

Figure 3. ${ }^{27}$ Al-NMR spectra of coal fly ash-based ZSM-5 synthesized from FFAE1 (A) and AL (B).

Table 2 shows that the ZSM- 5 properties such as crystal size and shape, Brunauer-Emmett-Teller (BET) surface area and Brønsted acid density varied with the composition of the feedstock as well as elemental composition of the products. The different characteristics of ZSM-5 synthesized from AL or FFAE1 could be due to the purity and composition of their silicon and aluminum precursors as shown in Figure 1 and Table 1. The BET surface area of H-AL-TPABr $\left(327 \mathrm{~m}^{2} / \mathrm{g}\right), \mathrm{H}-\mathrm{AL}-\mathrm{HDA}$ 
$\left(353 \mathrm{~m}^{2} / \mathrm{g}\right)$ and H-AL-PA $\left(39 \mathrm{~m}^{2} / \mathrm{g}\right)$ decreases with an increase in the size of their crystals (Table 2). H-FFAE1-TPABr, H-FFAE1-HDA and H-FFAE1-PA had high BET surface areas (between $353 \mathrm{~m}^{2} / \mathrm{g}$ and $459 \mathrm{~m}^{2} / \mathrm{g}$ ) compared to those of H-AL-TPABr, H-AL-HDA and H-AL-PA (Table 2). This could be due to the presence of unreacted fly ash in H-AL-TPABr, H-AL-HDA and H-AL-PA that affected their properties. Petrik and coworkers, Petrik, Bleken and coworkers, and Wang and coworkers, all reported that parameters such as the degree of polymerization of the silica, nature of the cations present, type of template and water content could influence the crystallization and morphology of ZSM-5 zeolite [17-20]. Sang and coworkers also reported that the Si/Al ratio and BET surface area of ZSM- 5 could be modified by changing the type of structure-directing agent [42].

Figure 4 shows that the $\mathrm{N}_{2}$ adsorption-desorption isotherms of all fly ash-based H-ZSM- 5 zeolites are that of type IV with the presence of a small hysteresis loop, which is characteristic of mesoporous materials [50].
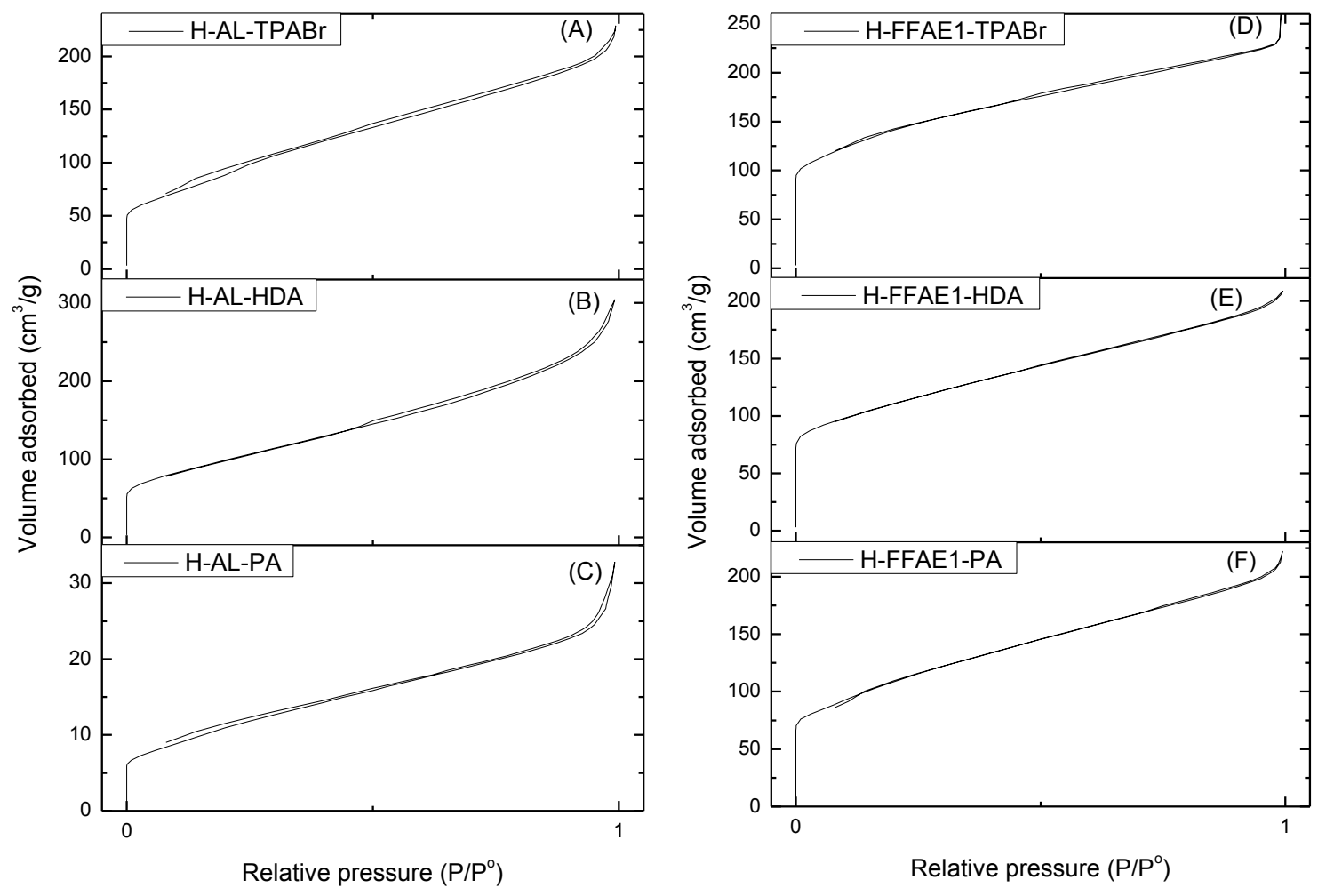

Figure 4. Adsorption-desorption isotherms of $\mathrm{N}_{2}$ at 77.41 $\mathrm{K}$ for $\mathrm{H}-\mathrm{ZSM}-5$ synthesized from AL (A-C) and FFAE1 (D-F).

The presence of unreacted quartz and mullite from fly ash in H-AL-TPABr, H-AL-HDA and H-AL-PA also affected their Methanol-to-Olefins (MTO) efficiency (Table 2 and Figure 5). The methanol conversion over H-AL-TPBAr, H-AL-HDA and H-AL-PA was 70\%, 73\% and 48\%, respectively, after $1 \mathrm{~h}$ on stream.

On the other hand, the use of a saturated oxalic acid solution in the treatment of fused fly ash extract prior to the hydrothermal synthesis led to the formation of a pure phase of ZSM-5, which led to a high methanol conversion (Table 2). The methanol conversions of H-FFAE1-TPABr, H-FFAE1-HDA and H-FFAE1-PA were $99 \%, 98 \%$ and $97 \%$ after $1 \mathrm{~h}$ on stream, respectively. A commercial H-ZSM-5, the same as that reported by Missengue and coworkers [13], was used as reference (Table 2). Moreover, all the synthesized fly ash-based ZSM-5 had good selectivity towards propylene. However, despite the presence of mesopores in their structure (Figure 4), they quickly became deactivated after $5 \mathrm{~h}$ on stream (Figure 5). Even though it is well known that zeolite acidity plays an important role in their catalytic applications [51-53], the MTO efficiency of H-AL-TPBAr, H-AL-HDA and H-AL-PA was 
mainly affected by the presence of unreacted fly ash, while that of H-FFAE1-TPABr, H-FFAE1-HDA and H-FFAE1-PA was affected by the size of their crystals. Hence, diffusional constraints were more likely to be the cause of the catalyst deactivation. Indeed, it was reported in the literature that the ZSM-5 crystal size affected its catalytic efficiency [54]. Takamitsu and coworkers reported that large ZSM- 5 crystals resulted in a quick deactivation of the catalyst [55]. Therefore, there is still a need to improve the chemical and physical properties of the synthesized fly ash-based ZSM-5 products in order for them to compete with a commercial ZSM-5. However, this study showed that the use of 1,6-hexanediamine as structure-directing agent led to the synthesis of a catalyst (H-FFAE1-HDA) with better MTO performance than that synthesized with the most commonly used ZSM- 5 template (TPABr) $[9,12,13,16,21,26,56]$. The difference in MTO performance of the synthesized fly ash-based ZSM-5 products was caused by the difference in their chemical and physical properties that were induced by the molecular structure of their template. Indeed, Wilson stated that templates are cationic species added to synthesis media to direct the polymerization of anionic building blocks that form the framework, and the charge distribution, size and geometric shape of the template influenced structure direction [57]. Therefore, tetrapropylammonium bromide (TPABr), 1,6-hexanediamine (HDA) and 1-propylamine (PA) would direct differently the polymerization of anionic building blocks that form ZSM- 5 because they have different molecular structures and positive charge distributions in solution. Bonilla and coworkers also reported that the properties of ZSM- 5 could be varied by using polymers of tetrapropylammonium hydroxide with different size, morphology and charge distribution [15].

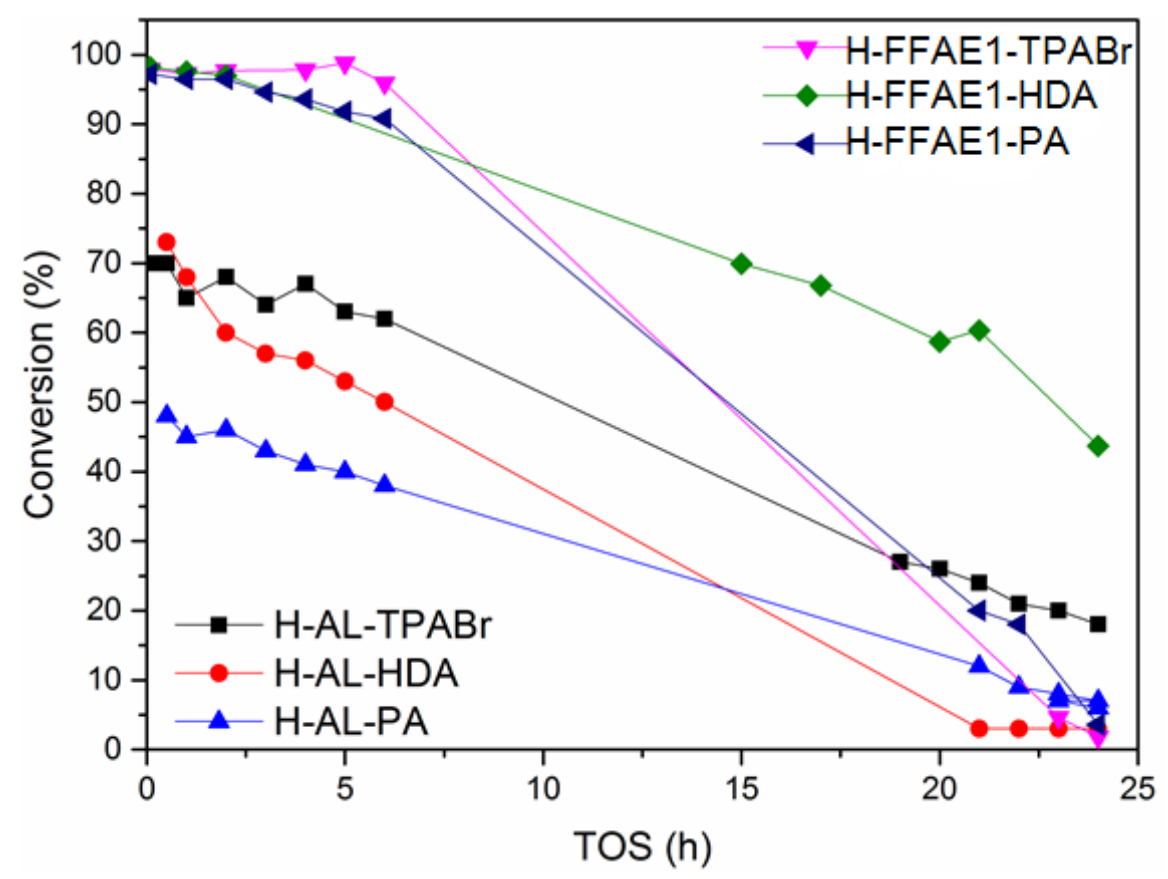

Figure 5. Methanol conversion of the fly ash-based ZSM-5, TOS = time on stream. 
Table 2. Properties of the fly ash-based ZSM-5, their methanol conversion and selectivity towards hydrocarbons.

\begin{tabular}{|c|c|c|c|c|c|c|c|c|c|}
\hline \multirow{3}{*}{ Catalyst } & \multicolumn{5}{|c|}{ Properties } & \multicolumn{4}{|c|}{ Methanol Conversion and Selectivity (e) } \\
\hline & \multirow{2}{*}{$\mathrm{Si} / \mathrm{Al}{ }^{(a)}$} & \multirow{2}{*}{$\mathrm{S}_{\mathrm{BET}}\left(\mathrm{m}^{2} / \mathrm{g}\right)^{(\mathrm{b})}$} & \multicolumn{2}{|c|}{ Crystal Size $(\mu \mathrm{m}){ }^{(\mathrm{c})}$} & \multirow{2}{*}{$\begin{array}{l}\text { Brønsted Acid Site Density } \\
\text { (mmol } \mathrm{H}^{+} / \mathrm{g} \text { of Catalyst) }\end{array}$} & \multirow{2}{*}{ Conversion [\%] } & \multirow{2}{*}{ Selectivity $C_{2}=[\%]$} & \multirow{2}{*}{ Selectivity $C_{3=}[\%]$} & \multirow{2}{*}{ Selectivity $\mathrm{C}_{4=}[\%]$} \\
\hline & & & Length & Width & & & & & \\
\hline H-AL-TPABr & 4 & 327 & $6.2 \pm 1.1$ & $5.6 \pm 1.2$ & 0.71 & 70 & 13 & 35 & 17 \\
\hline H-AL-HDA & 5 & 353 & $1.0 \pm 0.1$ & $0.6 \pm 0.1$ & 0.46 & 73 & 9 & 34 & 15 \\
\hline H-AL-PA & 5 & 39 & $18.9 \pm 2.0$ & $6.8 \pm 0.9$ & 0.42 & 48 & 18 & 32 & 12 \\
\hline H-FFAE-TPABr & 36 & 459 & $6.5 \pm 0.2$ & $2.6 \pm 0.5$ & 0.62 & 99 & 12 & 29 & 11 \\
\hline H-FFAE-HDA & 55 & 388 & $3.3 \pm 0.7$ & $1.1 \pm 0.2$ & 0.56 & 98 & 8 & 37 & 14 \\
\hline H-FFAE-PA & 42 & 353 & $3.1 \pm 0.4$ & $1.0 \pm 0.2$ & 0.53 & 97 & 6 & 38 & 16 \\
\hline H-ZSM-5 ${ }^{(\mathrm{f})}$ & 25 & 480 & I & / & 0.86 & 100 & 12 & 19 & 13 \\
\hline
\end{tabular}

(a) Elemental composition determined by inductively coupled plasma-optical emission spectrometry (ICP-OES); ${ }^{\left({ }^{b}\right)}$ Brunauer-Emmett-Teller (BET) surface area; ${ }^{(c)}$ determined using Image J software; ${ }^{(d)}$ measured via $\mathrm{H} / \mathrm{D}$-exchange technique; (e) reaction conditions: $\mathrm{MeOH}, 450{ }^{\circ} \mathrm{C}$, weight hour space velocity $(\mathrm{WHSV})=1.12 \mathrm{~g}(\mathrm{MeOH}) \cdot \mathrm{g}^{-1}(\mathrm{Catalyst}) \cdot \mathrm{h}^{-1}$, time on stream $(\mathrm{TOS})=1 \mathrm{~h} ;{ }^{(\mathrm{f})}$ commercial H-ZSM-5 with the same properties as those reported by Missengue and coworkers [13]. 


\section{Materials and Methods}

\subsection{Materials}

The coal fly ash (FA) used in this study was collected from a coal-fired power plant in the province of Mpumalanga (South Africa). Sulfuric acid (95-99\%) and 1-propylamine (99\%) were purchased from Merck (Sandton, Gauteng, South Africa). Tetrapropylammonium bromide (98\%), methanol (99.8\%), chloroform-d (99 atom \% D), chloroform ( $\geq 99.9 \%)$, trifluoroacetic anhydride $(\geq 99 \%)$, ammonium nitrate $(\geq 98 \%)$ and oxalic acid ( $\geq 99 \%)$ were obtained from Sigma-Aldrich (Saint-Quentin-Fallavier, France; and Aston Manor, Gauteng, South Africa). Sodium hydroxide (97\%) and 1,6-hexanediamine (99.5\%) were purchased from Kimix Chemical and Laboratory Supplies (Cape Town, Western Cape, South Africa).

\subsection{Methods}

\subsubsection{Synthesis of ZSM-5 from the Acid-Treated Fly Ash (AL)}

The acid-treated fly ash solid residue (AL) that was used as starting material in the synthesis of ZSM-5 zeolite was obtained by heating the mixture of coal fly ash (FA) and concentrated $\mathrm{H}_{2} \mathrm{SO}_{4}$ (95-99\%) at $200{ }^{\circ} \mathrm{C}$ for $2 \mathrm{~h}$. AL sample was mixed with fumed silica, sodium hydroxide and deionized water. Thereafter, tetrapropylammonium bromide (TPABr), 1,6-hexanediamine (HDA) or 1-propylamine (PA) was added. The molar regime used in the synthesis of fly ash based-ZSM-5 (AL-TPABr, AL-HDA and AL-PA) is presented in Table 3. After aging for $2 \mathrm{~h}$, the final mixture underwent hydrothermal synthesis at $160{ }^{\circ} \mathrm{C}$ for $72 \mathrm{~h}$. The obtained products were ion-exchanged 4 times with $0.5 \mathrm{M}$ ammonium nitrate with a solid/liquid ratio of $1: 10$ at $80^{\circ} \mathrm{C}$ and calcined in air at $550{ }^{\circ} \mathrm{C}$ for $3 \mathrm{~h}$ to prepare H-ZSM-5 samples. The prepared H-ZSM-5 samples were treated with an aqueous saturated solution of oxalic acid with a solid/liquid ratio of $1: 10$ at $80{ }^{\circ} \mathrm{C}$ for $6 \mathrm{~h}$.

\subsubsection{Synthesis of ZSM-5 from the Fused Fly Ash Extracts (FFAEs)}

Coal fly ash (FA) was fused with sodium hydroxide as suggested by Musyoka and coworkers [3]. Thereafter, silica was precipitated from a supernatant of the fused fly ash as suggested by Baldyga and coworkers [32]. The silica extract (FFAE) was treated with a saturated oxalic acid solution at $80^{\circ} \mathrm{C}$ for $6 \mathrm{~h}$ to obtain FFAE1. FFAE or FFAE1 was mixed with $\mathrm{NaOH}$ and deionized water. Thereafter, tetrapropylammonium bromide (TPABr) or 1,6-hexanediamine (HDA) or 1-propylamine (PA) was added to get the molar regime presented in Table 3. After aging for $30 \mathrm{~min}$, the obtained gel underwent hydrothermal crystallization at $160{ }^{\circ} \mathrm{C}$ for $72 \mathrm{~h}$ [58]. The synthesized products were ion-exchanged with $0.5 \mathrm{M}$ of ammonium nitrate to prepare the $\mathrm{H}$-form of the zeolite. The Brønsted acid site titration of the fly ash-based samples was performed using H/D-exchange isotope techniques, developed by Louis and coworkers [59].

Table 3. Molar regime of the formulation of fly ash-based ZSM-5.

\begin{tabular}{cc}
\hline Code Name & Molar Regime \\
\hline AL-TPABr & $\mathrm{Si}(6), \mathrm{Al}(1), \mathrm{Na}(2), \mathrm{H}_{2} \mathrm{O}(339), \mathrm{TPABr}(1)$ \\
AL-HDA & $\mathrm{Si}(6), \mathrm{Al}(1), \mathrm{Na}(2), \mathrm{H}_{2} \mathrm{O}(339), \mathrm{HDA}(3)$ \\
AL-PA & $\mathrm{Si}(6), \mathrm{Al}(1), \mathrm{Na}(2), \mathrm{H}_{2} \mathrm{O}(339), \mathrm{PA}(5)$ \\
FFAE-TPABr & $\mathrm{Si}(10), \mathrm{Al}(1), \mathrm{Na}(49), \mathrm{H}_{2} \mathrm{O}(3412), \mathrm{TPABr}(4)$ \\
FFAE1-TPABr & $\mathrm{Si}(42), \mathrm{Al}(1), \mathrm{Na}(31), \mathrm{H}_{2} \mathrm{O}(6313), \mathrm{TPABr}(7)$ \\
FFAAE1-HDA & $\mathrm{Si}(42), \mathrm{Al}(1), \mathrm{Na}(31), \mathrm{H}_{2} \mathrm{O}(6313), \mathrm{HDA}(20)$ \\
FFAE1-PA & $\mathrm{Si}(42), \mathrm{Al}(1), \mathrm{Na}(31), \mathrm{H}_{2} \mathrm{O}(6313), \mathrm{PA}(38)$ \\
\hline
\end{tabular}




\subsubsection{Methanol-to-Olefins (MTO) Catalytic Reaction over the Fly Ash-Based ZSM-5 Samples}

The fly ash-based H-form ZSM-5 (60 mg) was placed in a fixed-bed quartz reactor (Institute of Chemistry, UMR 7177, University of Strasbourg, Strasbourg, France) heated at $450{ }^{\circ} \mathrm{C}$ (heating ramp $15^{\circ} \mathrm{C} / \mathrm{min}$ ). After desorption of physisorbed water for $1 \mathrm{~h}$, methanol was fed to the reactor by a $\mathrm{N}_{2}$ flow $(20 \mathrm{~mL} / \mathrm{min})$, resulting in a weight hourly space velocity (WHSV) of $1.12 \mathrm{~g}(\mathrm{MeOH}) \cdot \mathrm{g}^{-1}($ Catalyst $) \cdot \mathrm{h}^{-1}$. Gas product samples $(1 \mathrm{~mL})$ were collected regularly during $24 \mathrm{~h}$ and analyzed using a Hewlett Packard 5890 gas chromatograph (GC) equipped with a PONA column and a FID (Institute of Chemistry, UMR 7177, University of Strasbourg, Strasbourg, France). The percentages of methanol conversion and the selectivity towards propylene/ethylene were determined as suggested by Losch and coworkers [26].

\subsubsection{Characterization Techniques}

PANalytical X-Ray diffractometer with PW3830 generator was used for X-ray diffraction (XRD) (iThemba LABS, Cape Town, South Africa). The morphology of as-synthesized fly ash-based ZSM-5 products and precursors was investigated using Hitachi X-650 scanning electron micro-analyzer (SEM) with a CDU-lead detector (University of the Western Cape, Cape Town, South Africa). Fourier transform infrared (FTIR) spectroscopy was performed for structural analysis using Perkin Elmer spectrum 100 spectrometer (University of the Western Cape, Cape Town, South Africa). The chemical composition of all the solid products was determined by inductively coupled plasma (ICP) using Varian 710-ES inductively coupled plasma-optical emission spectrometry (ICP-OES) instrument (University of the Western Cape, Cape Town, South Africa), after their total acid digestion using the method suggested by Missengue and coworkers [60]. ${ }^{27} \mathrm{Al}$ solid-state nuclear magnetic resonance $\left({ }^{27} \mathrm{Al} \mathrm{NMR}\right)$ was performed to distinguish the aluminum coordination of the synthesized fly ash-based ZSM-5 using Bruker Ascend TM 500 (University of the Western Cape, Cape Town, South Africa). Bruker UltraShield $300 \mathrm{MHz} / 54 \mathrm{~mm}$ spectrometer (Institute of Chemistry, UMR 7177, University of Strasbourg, Strasbourg, France) was used for ${ }^{1} \mathrm{H}$ NMR in determining the number of Brønsted acid sites. The MTO products were determined using Hewlett Packard 5890 gas chromatograph (HP 5890 GC) (Institute of Chemistry, UMR 7177, University of Strasbourg, Strasbourg, France). The BET surface area of the samples was determined using Autosorb IQ automated gas sorption analyzer (University of the Western Cape, Cape Town, South Africa).

\section{Conclusions}

The results presented in this study showed an innovative route for synthesizing ZSM- 5 zeolites from coal fly ash without extra silica source. The treatment of fused coal fly ash extract with oxalic acid prior to the hydrothermal synthesis process led to a pure ZSM-5 phase, while the zeolite synthesized from $\mathrm{H}_{2} \mathrm{SO}_{4}$-treated coal fly ash contained unreacted fly ash despite the addition of a large amount of fumed silica in the hydrothermal gel. Moreover, the presence of unreacted quartz and mullite from coal fly ash in some final products affected their properties and catalytic efficiency compared to the properties and catalytic efficiency of the final products without impurities from unreacted coal fly ash. The use of 1,6-hexanediamine as structure-directing agent led to the synthesis of an MTO catalyst that was more stable than that synthesized using tetrapropylammonium bromide, which is the most commonly used ZSM-5 template.

Acknowledgments: This work was supported by the National Research Foundation Protea program (grant number 29812PM) and the National Research Fund Luxembourg (grant number 5898454).

Author Contributions: Roland N. M. Missengue, Pit Losch, Nicholas M. Musyoka, Benoit Louis, Patrick Pale and Leslie F. Petrik conceived and designed the experiments; Roland N. M. Missengue and Pit Losch performed the experiments; Roland N. M. Missengue, Pit Losch, Nicholas M. Musyoka, Benoit Louis, Patrick Pale and Leslie F. Petrik analyzed the data; Benoit Louis, Patrick Pale and Leslie F. Petrik contributed reagents/materials/analysis tools; Roland N. M. Missengue, Pit Losch, Nicholas M. Musyoka, Benoit Louis, Patrick Pale and Leslie F. Petrik wrote the paper. 
Conflicts of Interest: The authors declare no conflict of interest.

\section{References}

1. Holler, H.; Wirsching, G.U. Zeolite formation from fly ash. Fortschr. Miner. 1985, 63, 21-43.

2. Ojha, K.; Pradhan, N.C.; Samanta, A.N. Zeolite from fly ash: Synthesis and characterization. Bull. Mater. Sci. 2004, 27, 555-564. [CrossRef]

3. Musyoka, N.M.; Petrik, L.F.; Gitari, W.M.; Balfour, G.; Hums, E. Optimization of hydrothermal synthesis of pure phase zeolite Na-P1 from South African coal fly ashes. J. Environ. Sci. Health A 2012, 47, 337-350. [CrossRef] [PubMed]

4. Belviso, C.; Cavalcante, F.; Lettino, A.; Fiore, S. Zeolite synthesized from fused coal fly ash at low temperature using seawater for crystallization. CCGP 2009, 1, 7-13. [CrossRef]

5. Chigondo, M.; Guyo, U.; Shumba, M.; Chigondo, F.; Nyamunda, B.; Moyo, M.; Nharingo, T. Synthesis and characterization of zeolites from coal fly ash (CFA). ESTIJ 2013, 3, 714-718.

6. Vadapalli, V.R.K.; Gitari, W.M.; Ellendt, A.; Petrik, L.F.; Balfour, G. Synthesis of zeolite P from coal fly ash derivative and its utilization in mine water remediation. S. Afr. J. Sci. 2010, 106, 1-7.

7. Adamczyk, Z.; Bialecka, B. Hydrothermal synthesis of zeolites from Polish coal fly ash. Pol. J. Environ. Stud. 2005, 14, 713-719.

8. Moutsatsou, A.; Karakasia, O.K.; Koukouzas, N.; Itskos, G.S.; Vasilatosc, C. Synthesis of zeolitic materials utilizing CFB-derived coal fly ash as a raw material. In Proceedings of the WanteEng-2nd International Conference on Engineering for Waste Valorisation, Patras, Greece, 2006.

9. Chareonpanich, M.; Namto, T.; Kongkachuichay, P.; Limtrakul, J. Synthesis of ZSM-5 zeolite from lignite fly ash and rice husk ash. Fuel Process. Technol. 2004, 85, 1623-1634. [CrossRef]

10. Flanigen, E.; Patton, R.L. Silica Polymorph. U.S. Patent 4073865, 14 February 1978.

11. Van der Gaag, F.J. ZSM-5 Type Zeolites: Synthesis and Use in Gasphase Reactions with Ammonia. Ph.D. Thesis, Delft University of Technology, Delft, The Netherlands, 1987.

12. Losch, P.; Boltz, M.; Louis, B.; Chavan, S.; Olsbye, U. Catalyst optimization for enhanced propylene formation in the MTO reaction. C. R. Chim. 2015, 18, 330-335. [CrossRef]

13. Missengue, R.N.M.; Losch, P.; Sedres, G.; Musyoka, N.M.; Fatoba, O.O.; Louis, B.; Pale, P.; Petrik, L.F. Transformation of South African coal fly ash into ZSM-5 zeolite and its application as an MTO catalyst. C. R. Chim. 2017, 20, 78-86. [CrossRef]

14. Narayanan, S.; Sultana, A.; Krishna, K.; Meriaudeau, P.; Naccache, C. Synthesis of ZSM-5 type zeolites with and without template and evaluation of physicochemical properties and aniline alkylation activity. Catal. Lett. 1995, 34, 129-138. [CrossRef]

15. Bonilla, G.; Diaz, I.; Tsapatsis, M.; Jeong, H.K.; Lee, Y.; Vlachos, D.G. Zeolite (MFI) crystal morphology control using organic structure-directing agents. Chem. Mater. 2004, 16, 5697-5705. [CrossRef]

16. Shirazi, L.; Jamshidi, E.; Ghasemi, M.R. The effect of Si / Al ratio of ZSM-5 zeolite on its morphology, acidity and crystal size. Cryst. Res. Technol. 2008, 43, 1300-1306. [CrossRef]

17. Petrik, L.F.; O'Connor, C.T.; Schwarz, S. The influence of various parameters on the morphology and crystal size of ZSM-5 and the relationship between morphology and crystal and propene oligomerization activity. Stud. Surf. Sci. Catal. 1995, 94, 517-524.

18. Petrik, L. The influence of cation, anion and water content on the rate of formation and pore size distribution of zeolite ZSM-5. S. Afr. J. Sci. 2009, 105, 251-257. [CrossRef]

19. Bleken, F.L.; Chavan, S.; Olsbye, U.; Boltz, M.; Ocampo, F.; Louis, B. Conversion of methanol into light olefins over ZSM-5 zeolite: Strategy to enhance propene selectivity. Appl. Catal. A 2012, 447-448, 178-185. [CrossRef]

20. Wang, J.; Groen, J.C.; Yue, W.; Zhou, W.; Coppens, M.O. Facile synthesis of ZSM-5 composites with hierarchical porosity. J. Mater. Chem. 2008, 18, 468-474. [CrossRef]

21. Kalyankar, A.N.; Choudhari, A.L.; Joshi, A.A. Low frequency dielectric properties of fly ash based zeolite ZSM-5. IJBAS 2011, 1, 59-63.

22. Reanvattana, N. Two-Stage Synthesis of High Purity ZSM-5 Zeolite from Coal Fly Ash and Rice Husk Ash. Master's Thesis, Chemical Engineering, Kasetsart University, Bangkok, Thailand, 2005. 
23. Xing, Z.; Hongyan, G. Preparation Method of Low-Cost ZSM-5 Type Zeolite Molecular Sieve, and Application Thereof. European Patent CN103787366 (A), 14 May 2014.

24. Lercher, J.; Jentys, A. Basic concepts in zeolite acid-base catalysis. In Proceedings of the 5th International Federation of European Zeolite Associations (FEZA) Conference, Valence, Spain, 3-7 July 2011; pp. 181-210.

25. Triantafillidis, C.S.; Evmiridis, N.; Nalbandian, L.; Vasalos, I.A. Performance of ZSM-5 as a fluid catalytic cracking catalyst additive: Effect of the total number of acid sites and particles size. Ind. Eng. Chem. Res. 1999, 38, 916-927. [CrossRef]

26. Losch, P.; Boltz, M.; Bernardon, C.; Louis, B.; Palcic, A.; Valtchev, V. Impact of external surface passivation of nano-ZSM-5 zeolites in the Methanol-to-Olefins reaction. Appl. Catal. A 2016, 509, 30-37. [CrossRef]

27. Van Dijk, C.P.; Solbakken, A.; Rovner, J.M. Methanol from Coal and Natural Gas. U.S. Patent 4,407,973 A, 4 October 1983.

28. Zaidi, H.A.; Pant, K.K. Activity of oxalic acid treated $\mathrm{ZnO} / \mathrm{CuO} / \mathrm{H}-\mathrm{ZSM}-5$ catalyst for the transformation of Methanol-to-Gasoline range hydrocarbons. Ind. Eng. Chem. Res. 2008, 47, 2970-2975. [CrossRef]

29. Moreno, N.; Querol, X.; Plana, F.; Andres, J.M.; Janssen, M.; Nugteren, H. Pure zeolite synthesis from silica extracted from coal fly ashes. J. Chem. Technol. Biotechnol. 2002, 77, 274-279. [CrossRef]

30. Guang-Hui, B.; Wei, T.; Xiang-Gang, W.; Jin-Guo, Q.; Peng, X.; Peng-Cheng, L. Alkali desilicated coal fly ash as substitute of bauxite in lime-soda sintering process for aluminum production. Trans. Nonferrous Met. Soc. China 2010, 20, 169-175.

31. Zhu, G.; Tan, W.; Sun, J.; Gong, Y.; Zhang, S.; Zhang, Z.; Liu, L. Effects and mechanism research of the desilication pre-treatment for high-aluminum fly ash. Energy Fuels 2013, 27, 6948-6954. [CrossRef]

32. Baldyga, J.; Jasinska, M.; Jodko, K.; Petelski, P. Precipitation of amorphous colloidal silica from aqueous solutions-aggregation problem. Chem. Eng. Sci. 2012, 77, 207-216. [CrossRef]

33. Liu, K.; Xue, J.; Zhu, J. Extracting Alumina from Coal Fly Ash Using Acid Sintering-Leaching Process. In Light Metals; Suarez, C.E., Ed.; John Wiley \& Sons, Inc.: Hoboken, NJ, USA, 2012.

34. Yao, Z.T.; Xia, M.S.; Sarker, P.K.; Chen, T. A review of the alumina recovery from coal fly ash, with a focus in China. Fuel 2014, 120, 74-85. [CrossRef]

35. Hattori, T.; Yashima, T. Zeolites and Microporous Crystals; Technology \& Engineering, Elsevier: Amsterdam, The Netherlands, 1994.

36. Singh, R.; Dutta, P.K. MFI: A Case Study of Zeolite Synthesis; Marcel Dekker, Inc.: Columbus, OH, USA, 2003.

37. Moliner, M. Zeolites and ordered porous solids: Fundamentals and applications-Basic principles of zeolite synthesis. In Proceedings of the 5th International FEZA Conference, Valence, Spain, 3-7 July 2011; pp. 37-65.

38. Yan, Z.; Ma, D.; Zhuang, J.; Liu, X.; Liu, X.; Han, X.; Bao, X.; Chang, F.; Xu, L.; Liu, Z. On the acid-dealumination of USY zeolite: A solid NMR investigation. J. Mol. Catal. A Chem. 2003, 194, $153-167$. [CrossRef]

39. Zhang, W.; Xin, H.; Yu, Y.; He, H. Oxalic acid treating of ZSM-5 zeolite for the enhanced photocatalytic activity of TiO2/H-ZSM-5. J. Adv. Oxid. Technol. 2014, 17, 359-364. [CrossRef]

40. Sazama, P.; Wichterlova, B.; Dedecek, J.; Tvaruskova, Z.; Musilova, Z.; Palumbo, L.; Sklenak, S.; Gonsiorova, O. FTIR and ${ }^{27}$ Al MAS NMR analysis of the effect of framework Al- and Si-defects in microand micro-mesoporous H-ZSM-5 on conversion of methanol to hydrocarbons. Microporous Mesoporous Mater. 2011, 143, 87-96. [CrossRef]

41. Treacy, M.M.J.; Higgins, J.B. Collection of Simulated XRD Power Patterns for Zeolites, 4th ed.; ELSEVIER: Amsterdam, The Netherlands, 2001.

42. Sang, S.; Chang, F.; Liu, Z.; He, C.; He, Y.; Xu, L. Difference of ZSM-5 zeolites synthesized with various templates. Catal. Today 2004, 93-95, 729-734. [CrossRef]

43. Abou Rida, M.; Harb, F. Synthesis and characterization of amorphous silica nanoparticles from aqueous silicates using cationic surfactants. J. Met. Mater. Miner. 2014, 24, 37-42.

44. Bass, J.L.; Turner, G.L. Anion distribution in sodium silicate solutions. Characterization by ${ }^{29} \mathrm{Si}$ NMR and infrared spectroscopies, and vapor phase osmometry. J. Phys. Chem. B 1997, 101, 10638-10644. [CrossRef]

45. Ali, M.A.; Brisdon, B.J.; Thomas, W.J. Synthesis, Characterization and Catalytic Activity of ZSM-5 Zeolites Having Variable Silicon-to-Aluminum Ratios. Appl. Catal. A 2003, 252, 149-162. [CrossRef]

46. Van der Gaag, F.J.; Jansen, J.C.; Vanberkkum, H. Template variation in the synthesis of zeolite ZSM-5. Appl. Catal. 1985, 17, 261-271. [CrossRef] 
47. Criado, M.; Fernandez-Jimenez, A.; Palomo, A. Alkali activation of fly ash: Effect of the $\mathrm{SiO}_{2} / \mathrm{Na}_{2} \mathrm{O}$ ratio part 1: FTIR study. Microporous Mesoporous Mater. 2007, 106, 180-191. [CrossRef]

48. Triantafillidis, K.S.; Nalbandian, L.; Trikalitis, P.N.; Ladavos, A.K.; Mavromustakos, T.; Nicolaides, C.P. Structure, compositional and acidic characteristics of nanosized amorphous or partially crystalline ZSM-5 zeolite-based materials. Microporous Mesoporous Mater. 2004, 75, 89-100. [CrossRef]

49. Byrappa, K.; Yoshimura, M. Handbook of Hydrothermal Technology; Noyes Publications/William Andrew Publishing, LLC: New York, NY, USA, 2001.

50. Lowell, S.; Shields, J.E.; Thomas, M.A.; Thommes, M. Characterization of Porous Solids and Powders: Surface Area, Pore Size and Density; Springer: New York, NY, USA, 2004.

51. Louis, B.; Pereira, M.M.; Santos, F.M.; Esteves, P.M.; Sommer, J. Alkane activation over acidic zeolites: The first step. Chem. Eur. J. 2010, 16, 573-576. [CrossRef] [PubMed]

52. Dai, W.; Wang, X.; Wu, G.; Guan, N.; Hunger, M.; Li, L. Methanol-to-Olefin conversion on silicoaluminophosphate catalysts: Effect of Brønsted acid sites and framework structures. ACS Catal. 2011, 1, 292-299. [CrossRef]

53. Chen, D.; Moljord, K.; Holmen, A. A methanol to olefins review: Diffusion, coke formation and deactivation on SAPO type catalysts. Microporous Macroporous Mater. 2012, 164, 239-250. [CrossRef]

54. Wan, Z.; Wang, C.; Yang, H.; Zhang, D. Effect of Crystal Size of ZSM-5 on its Catalytic Activity for Methanol to Gasoline Conversion. In CHEMECA 2013, Challenging Tomorrow, Brisbane, Australia, 29 September-2 October 2013; Engineers Media Pty Ltd., 1: Barton, Australia, 2013.

55. Takamitsu, Y.; Yamamoto, K.; Yoshida, S.; Ogawa, H.; Sano, T. Effect of crystal size and surface modification of ZSM-5 zeolites on conversion of ethanol to propylene. J. Porous Mater. 2014, 21, 433-440. [CrossRef]

56. Nicolaides, C.P. A novel family of solid acid catalysts: Substantially amorphous or partially crystalline zeolitic materials. Appl. Catal. A Gen. 1999, 185, 211-217. [CrossRef]

57. Wilson, S.T. Templating in molecular sieve synthesis. In Verified Synthesis of Zeolite Materials, 2nd ed.; Elsevier Science B.V: Amsterdam, The Netherlands, 2001; pp. 27-32.

58. Missengue, R.N.M.; Ameh, A.E.; Ndlovu, Z.N.; Hlatywayo, T.; Petrik, L.F. Process for Production of High Silica Content Zeolite from Fly Ash. Patent WO/2017/221192, 28 December 2017.

59. Louis, B.; Walspurger, S.; Sommer, J. Quantitative determination of Brønsted acid sites on zeolites: A new approach towards the chemical composition of zeolites. Catal. Lett. 2004, 93, 81-84. [CrossRef]

60. Missengue, R.N.M.; Musyoka, N.M.; Madzivire, G.; Babajide, O.; Fatoba, O.O.; Tuffin, M.; Petrik, L.F. Leaching and antimicrobial properties of silver nanoparticles loaded onto natural zeolite clinoptilolite by ion exchange and wet impregnation. J. Environ. Sci. Health A 2016, 51, 97-104. [CrossRef] [PubMed] 